\title{
Akt- and MAPK-mediated activation and secretion of MMP-9 into stroma in breast cancer cells upon heregulin treatment
}

\author{
SU JIN CHO ${ }^{1,2}$, MOON JUNG CHAE ${ }^{2}$, BONG KYUNG SHIN ${ }^{1,2}$, HAN KYEOM KIM ${ }^{1,2}$ and AEREE KIM ${ }^{1,2}$ \\ ${ }^{1}$ Department of Pathology, College of Medicine, ${ }^{2}$ Korea Lung Tissue Bank, \\ Korea University, 80 Guro-dong, Guro-gu, Seoul 152-703, Korea
}

Received October 23, 2007; Accepted November 26, 2007

\begin{abstract}
Several peptides, such as epidermal growth factor (EGF), heregulin (HRG) and transforming growth factor alpha $(\mathrm{TGF} \alpha)$, are ligands for EGFR family. Heregulin beta 1 (HRG-31) binds to ErbB-3 and -4 and plays important roles in the proliferation and tumorigenesis of breast cancer cells. We investigated proteins through which HRG treatment affects matrix metalloproteinase (MMP)-9 activity. Breast cancer cell lines, including SK-Br3, MCF-7 and MDA-MB-231, were treated with HRG- 31 . After $24 \mathrm{~h}$, the activity and expression levels of MMP-9 were increased, but MMP-2 activity was not changed. The increasing rates of MMP-9 activity and expression were most prominent in the SK-Br3 cell line. Upon treatment of SK-Br3 cells with HRG-B1, phosphorylation of Akt was increased showing a peak at $30 \mathrm{~min}$ after treatment, and the level decreased after $6 \mathrm{~h}$. The expression levels of Akt were not changed upon HRG-B1 treatment. Phosphorylation of extracellular signal-regulated kinase 1/2 (ERK-1/2), downstream molecules of Akt, was also increased by HRG-ß1 treatment. Pretreatment of LY294002, PI3K inhibitor, or PD98059, MAPK inhibitor, partially blocked the heregulin-induced MMP-9 activity. Furthermore, MMP-9 was found to be secreted in human breast cancer tissues. The present results suggest that Akt and MAPK mediate HRG-31 signaling to MMP-9.
\end{abstract}

\section{Introduction}

Invasion and metastasis are important factors for choice of primary therapy and patient's outcome. In the invasive and metastatic processes, transformed cells from in situ carcinoma should penetrate basement membrane and surrounding extracellular matrix (ECM). Protease derived from cancer

Correspondence to: Dr Aeree Kim, Department of Pathology, College of Medicine, Korea University, 80 Guro-dong, Guro-gu, Seoul 152-703, Korea

E-mail: ark@korea.ac.kr

Key words: Akt, MAPK, matrix metalloproteinase-9, breast cancer, heregulin cells can be involved in tumorigenesis, tumor growth and vascularization in addition to degradation of ECM: degradation of basement membrane results in the loss of physical barrier against malignant cells, and degradation of ECM provides malignant cells with pathways to new habitat. Degradation of basement membrane and stromal connective tissue components are very important steps in metastasis, and the molecules involved in these processes can be candidates as new prognostic markers in malignant diseases. Human matrix metalloproteinase (MMP) family consists of more than 20 members of homologous zinc-dependent endopeptidases and is capable of degrading ECM and basement membrane. They are divided into gelatinase, also known as type IV collagenase, stromelysins, matrilysins and membrane MMPs (1). MMP-9 and MMP-2 are classified as gelatinase. Upregulation of MMP-2 in colorectal carcinoma tissue and MMP-9 in colorectal adenoma have been reported $(2,3)$. In oral cancer, MMP-9 and MMP-2 have been suggested as a useful marker for identification of metastatic phenotype (4). MMP-9 expression has been shown to be mediated through activation of the MAPK and PI3K/Akt signaling pathways in an oral tongue squamous cell carcinoma-derived cell line (5).

Breast cancer is one of the most common cancers in women. In mammary carcinomas, overexpression of the ErbB-2 protein has been reported in one-third of invasive breast carcinoma cases and is associated with poor survival, metastatic potential, and resistance to specific chemotherapeutic treatments and hormone therapy $(6,7)$. ErbB-2 is generally considered an orphan receptor, since no receptor specific ligand has yet been identified (8). Ligand-independent homodimerization of ErbB-2 or ligand-dependent heterodimerization of ErbB-2 with ErbB-3 activates a downstream signaling pathway (9). Heregulin beta 1 (HRG-ß1) is known as a ligand for ErbB-3, and it can activate a wide range of intracellular pathways imparting various biological responses, such as cellular proliferation, maturation, survival, apoptosis and angiogenesis (10-13).

In this study, we sought to clarify if heregulin can induce heterodimerization of ErbB-2/ErbB-3 receptors and activate gelatinase. We studied i) expression profiles of ErbB-2 and ErbB3 in breast cancer cell lines, ii) the activation of gelatinase by the ligand for ErbB3, such as HRG in the ErbB-2 and ErbB-3-expressing breast cancer cell line, and iii) analysed the downstream signaling pathways. 


\section{Materials and methods}

Cell culture. Human breast cancer cell lines, SK-Br-3, MCF-7 and MDA-MB-231, were obtained from the American Type Culture Collection (Rockville, MD) and maintained in Dulbecco's modified Eagle's medium (DMEM) and Ham's F-12 medium (1:1, v/v) (Cambrex Bio Science Walkersville, Inc., Walkersville, MD) supplemented with $10 \%$ heat-inactivated fetal bovine serum (FBS; Gibco Laboratories, Grand Island, $\mathrm{NY}$ ). These cell lines were cultured in a $37^{\circ} \mathrm{C}$ humidified atmosphere containing 95\% air and $5 \% \mathrm{CO}_{2}$ and were split twice a week. Heregulin (R\&D Systems, Minneapolis, MN) at $25 \mathrm{ng} / \mathrm{ml}$ was applied, LY294002 (Calbiochem, San Diego, CA) at $10 \mu \mathrm{M}$ and PD98059 (Calbiochem) at $20 \mu \mathrm{M}$. After appropriate treatment, cells were washed with phosphatebuffered saline (PBS) and then harvested with a scraper. The cell pellet and conditioned media were stored at $-80^{\circ} \mathrm{C}$ until use. Cell pellet was resuspended in $100 \mu \mathrm{l}$ of lysis buffer and then lysed with sonicator for immuno-blot analysis, and conditioned media were used for immuno-blot analysis and gelatin zymography.

Cellular protein preparation. After appropriate treatment, cells were washed with PBS and then harvested with a scraper. The cell pellet was resuspended in $100 \mu 1$ of lysis buffer and then lysed with sonicator. The lysate was centrifuged for $30 \mathrm{~min}$ at $20,000 \mathrm{x} \mathrm{g}$, and $4^{\circ} \mathrm{C}$, and then the supernatant was transferred to a new tube. The protein concentration was measured using Bradford assay.

Immuno-blot analysis. Immuno-blot analysis was performed as previously described (14). Briefly, cells were lysed in NP-40 lysis buffer $(50 \mathrm{mM}$ Tris- $\mathrm{HCl}, \mathrm{pH} 7.4,150 \mathrm{mM} \mathrm{NaCl}, 0.5 \%$ NP-40, $50 \mathrm{mM} \mathrm{NaF}, 1 \mathrm{mM} \mathrm{Na} \mathrm{VO}_{4}, 1 \mathrm{mM}$ phenylmethylsulfonyl fluoride, $25 \mu \mathrm{g} / \mathrm{ml}$ leupeptin, $25 \mu \mathrm{g} / \mathrm{ml}$ aprotinin). The supernatants were cleared by centrifugation. Protein concentrations were measured using the Coomassie plus protein assay reagent (Pierce Chemical Co., Rockford, IL). Protein lysates (40 $\mu \mathrm{g} / \mathrm{lane})$ were electrophoresed (Bio-Rad, Hercules, CA) on an $8 \%$ SDS polyacrylamide gel and transferred to nitrocellulose membranes. Membranes were blocked by incubation in 5\% skim-milk for $1 \mathrm{~h}$, washed 3 times, and probed with appropriate antibody. MMP-2, MMP-9 (Chemicon International, Temecula, CA), ErbB-2 (Upstate, Lake Placid, NY), ErbB-3 (NeoMarker, Fremont, CA), Akt, p-Akt, ERK-1/2 and p-ERK-1/2 (Cell Signaling Technology, Beverly, MA) were used. After overnight incubation, membranes were washed three times and incubated with secondary antibody solution for $1 \mathrm{~h}$. The membrane was washed 3 times for $30 \mathrm{~min}$ and then washed once with TBS for $5 \mathrm{~min}$. Protein detection and quantitation were carried out using ECL solution (Amersham, Arlington, IL) on X-ray film (Pierce, Rockford, IL).

Gelatin zymography. Activities of MMP-9 and MMP-2 were detected by gelatin zymography. Breast cancer cell lines, such as SK-Br3, MCF-7 and MDA-MB-231, were incubated with heregulin in serum-free and phenol red-free DMEM/F-12 media for appropriate time. Collected conditioned media were loaded onto an $8 \%$ polyacrylamide gel which had been impregnated with $0.1 \%$ gelatin (Sigma, St. Louis, MO). Electrophoresis was performed at a constant voltage of $100 \mathrm{~V}$. After electrophoresis, the gel was washed twice with $2.5 \%$ Triton $\mathrm{X}-100$ for $30 \mathrm{~min}$ to remove SDS, and the gel was then incubated in a buffer, containing $50 \mathrm{mM}$ Tris- $\mathrm{Cl}$ (pH 7.6), $200 \mathrm{mM} \mathrm{NaCl}$ and $5 \mathrm{mM} \mathrm{CaCl}_{2}$, for $48 \mathrm{~h}$ at $37^{\circ} \mathrm{C}$. The gel was stained with $0.5 \%$ Coomassie blue for $2 \mathrm{~h}$ and destained in solution containing $10 \%$ glacial acetic acid and $30 \%$ methanol. MMP-9 activity was detected as a clear zone in a dark blue field.

Immunohistochemstry (IHC). For immunohistochemical studies, 5 cases from each group, which represented normal stroma, fibroadenoma, ductal carcinoma in situ and invasive ductal carcinoma, were selected from the files of the Department of Pathology. Immunohistochemical staining was performed using the standard streptavidin-biotinperoxidase complex method using automated staining system (Autostainer Plus, Dako, Denmark). Antigen retrieval was performed by microwave oven treatment for $15 \mathrm{~min}$ in $0.01 \mathrm{M}$ citrate buffer ( $\mathrm{pH}$ 6.0). Endogenous peroxidase in tissue sections was blocked using $3 \%$ hydrogen peroxide for $20 \mathrm{~min}$. Slides were then incubated with appropriately diluted primary antibodies (Monoclonal anti-human MMP-9 antibody, 1:100, Chemicon international, Temecula, CA). After washing with TBS, tissue sections were incubated with biotinylated secondary antibody and then with diaminobenzidine (DAB) substrate, as provided in a Dako Envision kit (Dako). Nuclei were counter-stained with hematoxylin. Slides were then dehydrated, mounted, and examined.

\section{Results}

Expression levels of ErbB-2, -3 and MMP-9 in breast cancer cell lines. First, we examined the expression levels of receptors involved in erbB-2 downstream signaling pathway, such as erbB-2 and -3 and MMP-2 and MMP-9 secreted in cancer cell lines by immuno-blot analysis. As shown in Fig. 1, cancer cells expressed both erbB-2 and -3 . ErbB-2 protein was highly expressed in $\mathrm{SK}-\mathrm{Br} 3$, whereas the expression was low in MCF-7 and MDA-MB-231 cells (Fig. 1A). ErbB-3 levels were relatively low in SK-Br3 cells compared to MCF-7 and MDA-MB-231 cells (Fig. 1A). Phosphorylation levels of Akt in SK-Br3 cells were higher than other cell lines (data not shown). Secretion of MMP-9 and MMP-2 was confirmed in all three breast cancer cell lines (Fig. 1B).

Upregulation of MMP-9 upon heregulin treatment. The ErbB-2/ErbB-3 complex is believed to be the most biologically active EGFR family hetero-dimer $(15,16)$. Secretion levels of MMP-9 and MMP-2 upon heregulin (HRG, R\&D Systems) treatment were examined in breast cancer cell lines by gelatin zymography (Fig. 2A). Heregulin treatment did not upregulate MMP-2 in all three cell lines. However, the expression level of MMP-9 was prominently increased in SK-Br3 cells upon heregulin treatment, whereas heregulin did not upregulate MMP-9 expression in MDA-MB-231 and MCF-7 cells. Upregulation of MMP-9 in SK-Br3 cell lines upon heregulin treatment was confirmed by Western blot analysis (Fig. 2B). 


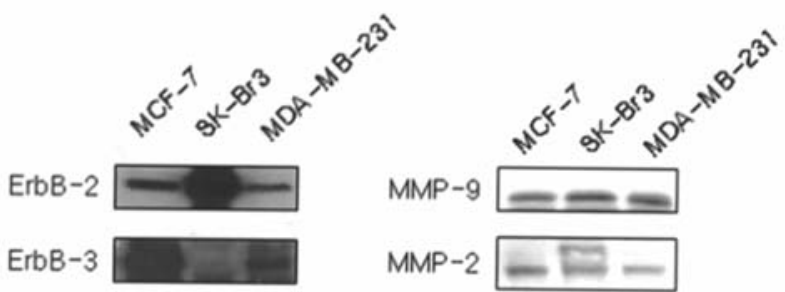

A

B

Figure 1. Endogenous protein levels of ErbB-2 and ErbB-3 in human breast cancer cell lines. (A) Western blot analysis was carried out to detect endogenous expression levels of ErbB-2 and ErbB-3 proteins. Each lane was loaded with $40 \mu \mathrm{g}$ of total cellular protein extract. (B) Western blot analysis was carried out to detect levels of secreted MMP-9 and MMP-2 proteins. Each cell lines were seeded onto 6-well plates and incubated for $24 \mathrm{~h}$. Ten percent FBS containing media were displaced with serum- and phenol red-free DMEM/F-12 media. After $24 \mathrm{~h}$ of further incubation, media were harvested from each well and loaded onto an $8 \%$ polyacrylamide gel, as described in Materials and methods.

A
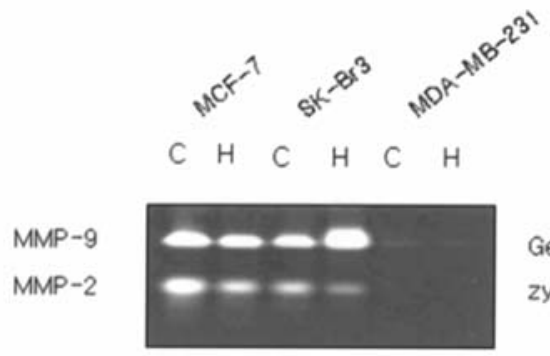

Gelatin

zymography

B

MMP-9

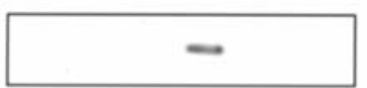

Western blot

Figure 2. MMP-9 expression levels induced by heregulin treatment in human breast cancer cells. (A) Each cell line was seeded onto 6-well plates and incubated for $24 \mathrm{~h}$. Media containing 10\% FBS were displaced with serum- and phenol red-free DMEM/F-12 media. After $24 \mathrm{~h}$ of further incubation, cells were washed twice with PBS and then treated with $25 \mathrm{ng} / \mathrm{ml}$ heregulin. After additional $24 \mathrm{~h}$ of incubation, media were harvested from each well and loaded onto an $8 \%$ polyacrylamide gel impregnated with $0.1 \%$ gelatin, as described in Materials and methods. (B) Previously prepared media were loaded onto an $8 \%$ polyacrylamide gel and probed against MMP-9 antibody. C, control; and H, heregulin group treated for $24 \mathrm{~h}$.

Activation of Akt and MAPK in breast cancer cell lines upon heregulin treatment. Activities of Akt and MAPK in breast cancer cell lines upon heregulin treatment were examined by Western blot analysis. Thus, serum-starved SK-Br3 cells were treated with $25 \mathrm{ng} / \mathrm{ml}$ of HRG. As shown in Fig. 3, although protein levels of Akt were not changed, phosphorylation of Akt was prominently increased. Activity of MAPK was increased in both SK-Br3 and MCF-7 cells, however, MAPK level was too low in MDA-MB-231 compared to other cell lines, therefore it was difficult to detect p-MAPK.

Activation levels of Akt, MAPK and MMP-9 in SK-Br3 cells upon heregulin treatment. Serum-starved SK-Br3 cells were treated with $25 \mathrm{ng} / \mathrm{ml}$ of HRG. Fig. 4 shows rapid response

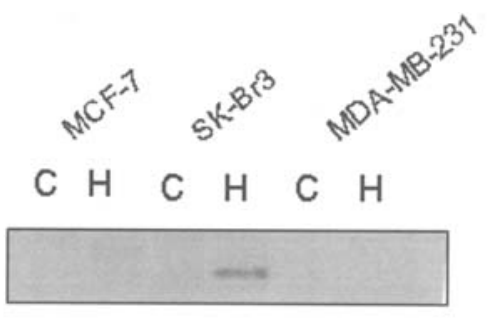

Akt

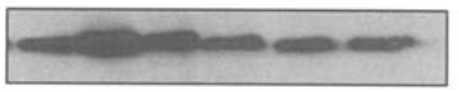

P-MAPK

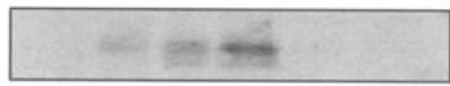

MAPK

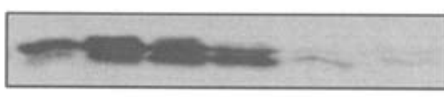

$\beta$-actin

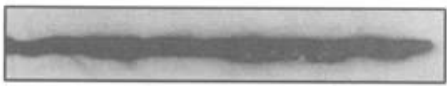

Figure 3. Activity of Akt and MAPK induced by heregulin treatment. Each cell line was incubated under serum-free and phenol red-free condition. After $24 \mathrm{~h}$, cells were washed twice with PBS and then treated with $25 \mathrm{ng} / \mathrm{ml}$ heregulin. After $24 \mathrm{~h}$ of incubation, media and cell pellet were harvested. Cellular proteins extracted as described in Materials and methods were loaded onto an $8 \%$ SDS polyacrylamide gel and probed against appropriate antibody. $\mathrm{B}$-actin protein was used as loading control. $\mathrm{C}$, control; and $\mathrm{H}$, heregulin group treated for $24 \mathrm{~h}$.

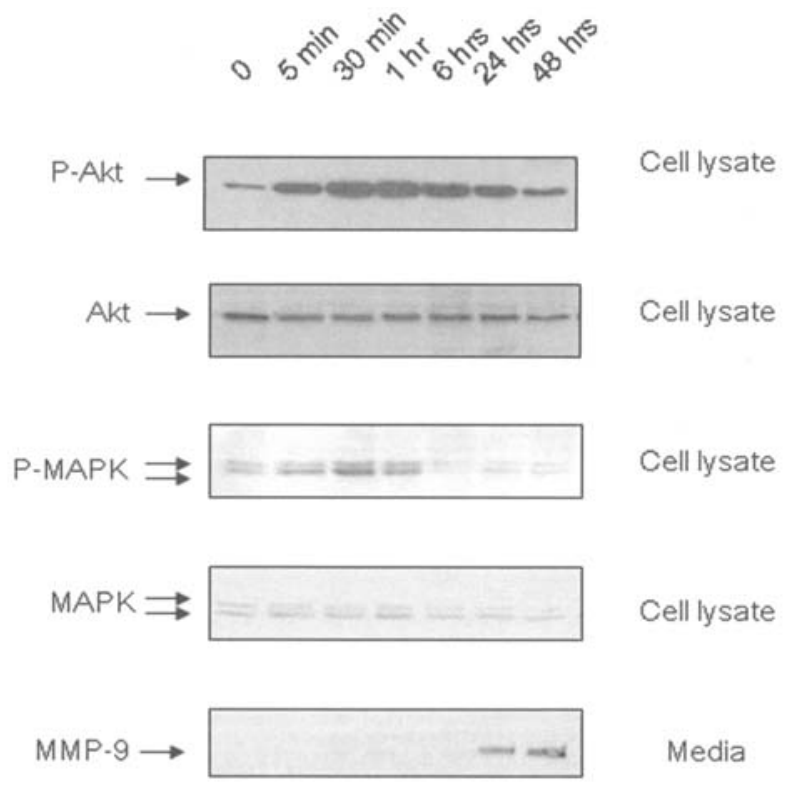

Figure 4. Time-dependent activity of Akt and MAPK upon heregulin treatment. SK-Br3 cells were incubated under serum-free and phenol red-free condition. After $24 \mathrm{~h}$, cells were washed twice with PBS and then treated with $25 \mathrm{ng} / \mathrm{ml}$ heregulin. After indicated time, media and cell pellet were harvested. Media and protein extract obtained from cell pellet were loaded onto an $8 \%$ SDS polyacrylamide gel and probed against appropriate antibody.

of Akt and MAPK to HRG treatment: Akt was activated within $5 \mathrm{~min}$ and showed peak at $30 \mathrm{~min}$ after heregulin treatment. After $6 \mathrm{~h}$, the level decreased slowly. In MCF-7 cells, Akt phosphorylation showed the highest level in $30 \mathrm{~min}$ after treatment and the level was decreased to $20 \%$ at $6 \mathrm{~h}$ 


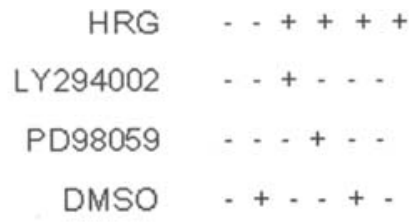

\section{Gelatin zymography}

MMP-9

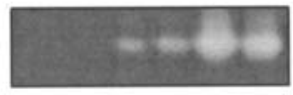

Supernatant

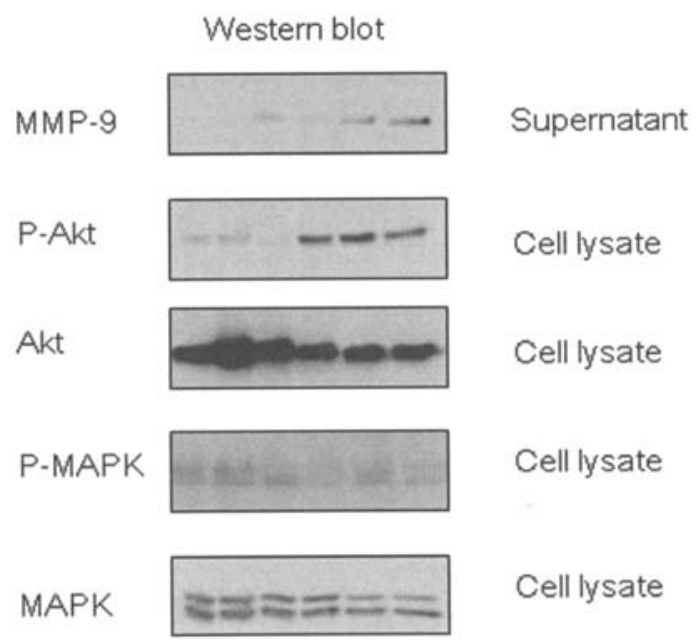

Figure 5. Effects of LY294002 and PD98059 on MMP-9 secretion in SK-Br3 cells. SK-Br3 cells were incubated under serum-free and phenol red-free condition. After $24 \mathrm{~h}$, cells were washed twice with PBS and then pre-treated with LY294002 or PD98059 prior to HRG-B1 treatment. After further incubation for $24 \mathrm{~h}$, media were harvested for gelatin zymography and Western blot analysis, and the cell pellet for Western blot analysis.

compared to the peak (data not shown). In MDA-MB-231 cells, however Akt phosphorylation was hardly increased (data not shown). The expression levels of Akt were not changed in all three cell lines upon HRG treatment. Phosphorylation of extracellular signal-regulated kinase $1 / 2$
(ERK-1/2), down-stream molecules of Akt, was also increased by HRG treatment, but its duration was shorter than Akt.

Pretreatment with LY294002, PI3K inhibitor, or PD98059, $M A P K$ inhibitor, partially blocked the MMP-9 activity. To examine whether PI3K and MAPK mediate the secretion of MMP-9 upon heregulin treatment, specific inhibitors were used to determine their effects on gelatinase activity. Thus, SK-Br3 cells were pre-incubated with $10 \mu \mathrm{M}$ LY294002 (PI3K inhibitor; Calbiochem) or $20 \mu \mathrm{M}$ PD98059 (Calbiochem) for $1 \mathrm{~h}$ prior to the HRG-B1 treatment. PD98059 blocked the activation of MAPK and LY294002 blocked phosphorylation of Akt. Under this condition, MMP-9 expression was significantly inhibited as confirmed by gelatin zymography and immuno-blot against MMP-9 antibody (Fig. 5).

Immunohistochemical detection of MMP-9 in normal breast tissue, ductal carcinoma in situ and invasive ductal carcinoma. Tumor cells showed extensive and strong MMP-9 expression patterns. Cells in surrounding invasive stroma, such as inflammatory cells and fibroblasts, also expressed MMP-9. The intensity of MMP-9 expression in normal ductal epithelial cells was weaker than in cancer cells, and no expression of MMP-9 was detected in stroma of normal or ductal carcinoma in situ (Fig. 6).

\section{Discussion}

In this study, we demonstrated that heregulin-induced upregulation of MMP-9 secretion was mediated by the PI3K/Akt pathway. SK-Br3 cell showed characteristics similar to Her-2 type breast cancer cells overexpressing ErbB-2, but not estrogen receptor (ER) and ErbB-3 proteins are expressed in SK-Br3 cells, but ErbB-4 proteins are not (17). As seen in Fig. 1A, ErbB-2 levels were high in SK-Br3 cells and heregulin treatment induces ErbB-2 activation through ErbB-3 or ErbB-4. All three cell lines used in this experiment did not express ErbB-4 $(17,18)$. Especially in breast cancer, heregulin induced heterodimerization between
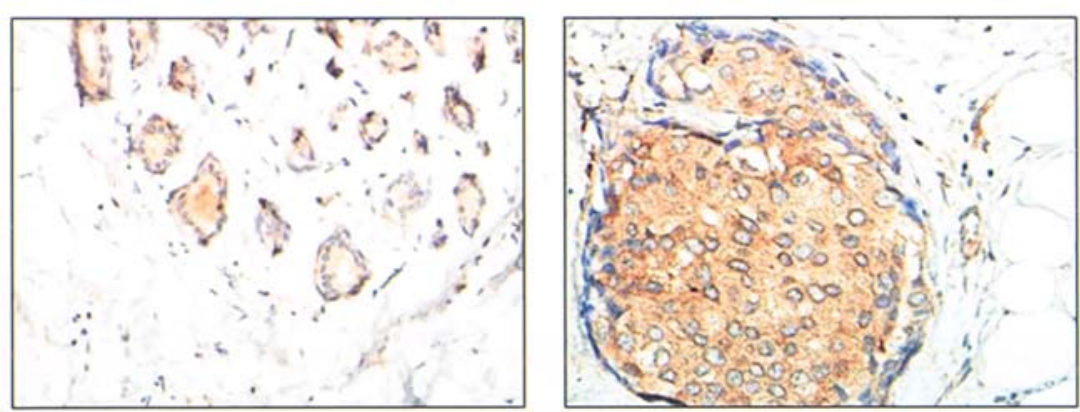

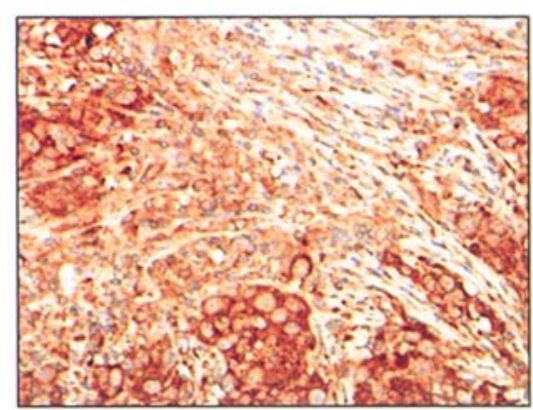

\section{Normal}


ErbB-2 and -3 and this heterodimerization plays an important role in signaling heregulin-mediated Akt activation $(18,19)$. In addition, Kim et al reported that heregulin stimulates the heterodimerization between ErbB-2 and ErbB-3 in mammary tumor-derived breast cancer cells (20). Secretion levels of MMP-9 and MMP-2 in breast cancer cells used in this study were not significantly different from each other (Fig. 1B). Upon heregulin treatment, activities and secretion levels of MMP-9 were upregulated only in SK-Br3 cells (Fig. 2). Therefore, these results suggest that heregulin induced the MMP-9 activation through ErbB-2/ErbB-3 heterodimerization in $\mathrm{SK}-\mathrm{Br} 3$ cells.

Hyperactivation of PI3K/Akt pathway plays an important role in tumor progression. The serine/threonine protein kinase Akt is downstream of many growth factor signaling cascades, and the activation of Akt pathway has been suggested as a major event in the survival and function of breast cancer cells. In the present study, to elucidate whether heregulin treatment induces activation of Akt in breast cancer cells, we examined the Akt phosphorylation levels after $24 \mathrm{~h}$ of heregulin treatment. In SK-Br3 cells, the level of p-Akt was increased the highest compared to those of MCF-7 and MDA-MB-231 cells (Fig. 3), and the level in SK-Br3 cells peaked at $30 \mathrm{~min}$ after heregulin treatment and decreased after $6 \mathrm{~h}$ (Fig. 4).

Concomitantly, phosphorylation of ERK-1/2 MAPK was also increased in SK-Br3 cells. ERK-1/2 MAPK has been detected in many primary human breast cancer (21-23). ERK-1/2 responds to various kinds of mitogens and growth factors to initiate changes in proliferation, differentiation and cell death, and is the most important member of the MAPK family, especially in breast cancer. In SK-Br3 cells, phosphorylation levels of ERK-1/2 were elevated immediately after heregulin treatment and peaked at $30 \mathrm{~min}$, however the protein levels were not changed (Fig. 4). After 24 h, secreted MMP-9 levels were detectable for Western blot analysis. In MCF-7 cells and MDA-MB-231 cells, however, phosphorylation of ERK-1/2 was also increased, but it peaked at different time-points (data not shown). Furthermore, although Akt or ERK-1/2 was activated by heregulin, MMP-9 levels were not changed in MCF-7 and MDA-MB-231 (Fig. 1). Therefore, these results suggest that heregulin could induce the expression of MMP-9 via Akt or ERK-1/2 only in SK-Br3 cells.

MMP-9 is a gelatinase and its association in invasion, metastasis and angiogenesis has been suggested (24-26). However, the pathway through which heregulin induces the MMP-9 activation in breast cancer has not been identified. To validate whether the Akt or MAPK is the mediator of the pathway, we treated the SK-Br3 cells with the inhibitor of Akt or MAPK prior to heregulin treatment. LY294002, PI3K inhibitor, blocked the Akt phosphorylation as expected and MMP-9 expression was also decreased (Fig. 5). Efficacy of PD98059 was confirmed by decreased levels of p-MAPK, and MMP-9 expression levels were also inhibited under this condition (Fig. 5). These results indicate that the heregulininduced expression of MMP-9 was mediated by Akt and ERK-1/2 MAPK. Although LY294002 and PD98059 inhibited heregulin-induced MMP-9 secretion, individually they could not completely block the signal. This might be due to the diversity of signal pathway related to Akt or ERK-1/2.

Matrix metalloproteinase is essential for tumor invasion and metastasis. In vitro, MMP-9 is detected mostly in the supernatant of tumor cells, and most of previous studies have focused on cancer cells and neglected the expression of MMP-9 in the tumor stroma $(24,27,28)$. The number of cases in the present study was limited, therefore, we could not draw statistical conclusions, nevertheless, immunohistochemistry revealed that MMP-9 was expressed not only in tumor cells but also in fibrous stroma, inflammatory cells, fibroblast and endothelial cells. These findings suggest that cancer cells themselves as well as interaction between cancer cells and stroma are very important in tumor progression. Further studies using clinical cases with paraffin tissue, clinical data and follow-up data are needed to clearly define the role of MMP-9 in progression of breast carcinoma and relationship between MMP-9 and Akt activation.

\section{Acknowledgments}

This study was supported by Special Research Materials Banks grant from the Ministry of Science and Technology/ Korea Science and Engineering Foundation (KOSEF, R212002-000-00015-0) and Korea University Grant (K0509651).

\section{References}

1. Malemud CJ: Matrix metalloproteinases (MMPs) in health and disease: an overview. Front Biosci 11: 1696-1701, 2006.

2. Cho YB, Lee YW, Song SY, Shin HJ, Yun SH and Chun HK: Matrix metalloproteinase- 9 activity is associated with poor prognosis in T3-T4 node-negative colorectal cancer. Hum Pathol (In press).

3. Gimeno-García AZ, Santana-Rodríguez A, Jiménez A, et al: Up-regulation of gelatinases in the colorectal adenoma-carcinoma sequence. Eur J Cancer 42: 3246-3252, 2006.

4. Patel BP, Shah SV, Shukla SN, Shah PM and Patel PS: Clinical significance of MMP-2 and MMP-9 in patients with oral cancer. Head Neck 29: 564-572, 2007.

5. O-Charoenrat P, Wongkajornsilp A, Rhys-Evans $\mathrm{PH}$ and Eccles SA: Signaling pathways required for matrix metalloproteinase- 9 induction by betacellulin in head-and-neck squamous carcinoma cells. Int J Cancer 111: 174-183, 2004.

6. Slamon DJ, Clark GM, Wong SG, Levin WJ, Ullrich A and McGuire WL: Human breast cancer: correlation of relapse and survival with amplification of the HER-2/neu oncogene. Science 235: 177-182, 1987.

7. Arteaga CL, Moulder SL and Yakes FM: HER (erbB) tyrosine kinase inhibitors in the treatment of breast cancer. Semin Oncol 29: 4-10, 2002.

8. Riese DJ II and Stern DF: Specificity within the EGF family/ ErbB receptor family signaling network. Bioessays 20: 41-48, 1998.

9. Graus-Porta D, Beerli RR, Daly JM and Hynes NE: ErbB-2, the preferred heterodimerization partner of all ErbB receptors, is a mediator of lateral signaling. EMBO J 16: 1647-1655, 1997.

10. Holbro T, Beerli RR, Maurer F, et al: The ErbB2/ErbB3 heterodimer functions as an oncogenic unit: ErbB2 requires ErbB3 to drive breast tumor cell proliferation. Proc Natl Acad Sci USA 100: 8933-8938, 2003.

11. Chang HW, Aoki M, Fruman D, et al: Transformation of chicken cells by the gene encoding the catalytic subunit of PI 3-kinase. Science 276: 1848-1850, 1977.

12. Hermanto U, Zong CS and Wang LH: ErbB2-overexpressing human mammary carcinoma cells display an increased requirement for the phosphatidylinositol 3-kinase signaling pathway in anchorage-independent growth. Oncogene 20: 7551-7562, 2001

13. Pearson G, Robinson F, Beers Gibson T, et al: Mitogen-activated protein (MAP) kinase pathways: regulation and physiological functions. Endocr Rev 22: 153-183, 2001. 
14. Cho SJ, La M, Ahn JK, Meadows GG and Joe CO: Tobmediated cross-talk between MARCKS phosphorylation and ErbB-2 activation. Biochem Biophys Res Commun 283: 273-277, 2001.

15. Anzick SL, Kononen J, Walker RL, et al: AIB1, a steroid receptor coactivator amplified in breast and ovarian cancer. Science 277: 965-968, 1997.

16. Riese DJ II, van Raaij TM, Plowman GD, Andrews GC and Stern DF: The cellular response to neuregulins is governed by complex interactions of the erbB receptor family. Mol Cell Biol 15: 5770-5776, 1995.

17. De Fazio A, Chiew YE, Sini RL, Janes PW and Sutherland RL: Expression of c-erbB receptors, heregulin and oestrogen receptor in human breast cell lines. Int J Cancer 87: 487-498, 2000.

18. Schmitt M, Walker MP, Richards RG, et al: Expression of heregulin by mouse mammary tumor cells: role in activation of ErbB receptors. Mol Carcinog 45: 490-505, 2006.

19. Way TD and Lin JK: Role of HER2/HER3 co-receptor in breast carcinogenesis. Future Oncol 1: 841-849, 2005.

20. Kim A, Liu B, Ordonez-Ercan D, et al: Functional interaction between mouse erbB3 and wild-type rat c-neu transgenic mouse mammary tumor cells. Breast Cancer Res 7: R708-R718, 2005.

21. Sivaraman VS, Wang H, Nuovo GJ and Malbon CC: Hyperexpression of mitogen-activated protein kinase in human breast cancer. J Clin Invest 99: 1478-1483, 1997.
22. Loda M, Capodieci P, Mishra R, et al: Expression of mitogenactivated protein kinase phosphatase- 1 in the early phase of human epithelial carcinogenesis. Am J Pathol 149: 1553-1564, 1996.

23. Maemura M, Iino Y, Koibuchi Y, Yokoe T and Morishita Y: Mitogen-activated protein kinase cascade in breast cancer. Oncology 57: 37-44, 1999.

24. Vizoso FJ, Gonzalez LO, Corte MD, et al: Study of matrix metalloproteinases and their inhibitors in breast cancer. $\mathrm{Br} \mathbf{J}$ Cancer 96: 903-911, 2007.

25. Tummalapalli P, Spomar D, Gondi CS, Olivero WC, Gujrati M, Dinh DH and Rao JS: RNAi-mediated abrogation of cathepsin $\mathrm{B}$ and MMP-9 gene expression in a malignant meningioma cell line leads to decreased tumor growth, invasion and angiogenesis. Int J Oncol 31: 1039-1050, 2007.

26. Zheng H, Takahashi H, Murai Y, et al: Expressions of MMP-2, MMP-9 and VEGF are closely linked to growth, invasion, metastasis and angiogenesis of gastric carcinoma. Anticancer Res 26: 3579-383, 2006.

27. Hao L, Zhang C, Qiu Y, et al: Recombination of CXCR4, VEGF, and MMP-9 predicting lymph node metastasis in human breast cancer. Cancer Lett 253: 34-42, 2007.

28. Li HC, Cao DC, Liu Y, et al: Prognostic value of matrix metalloproteinases (MMP-2 and MMP-9) in patients with lymph node-negative breast carcinoma. Breast Cancer Res Treat 88: $75-85,2004$ 